\title{
Equivalence of Additivity Questions in Quantum Information Theory
}

\section{Peter W. Shor ${ }^{\star}$}

AT\&T Labs Research, Florham Park, NJ 07922, USA

Erratum published online: 2 April 2004 - (c) Springer-Verlag 2004

Commun. Math. Phys. 246, 453-472 (2004)

Unfortunately, an editing error occurred in the first reference of the article, which appears in this issue, when the article was published "online".

Please note that the first reference should read as follows:

\section{References}

1. Audenaert, K.M.R., Braunstein, S.L.: On strong superadditivity of the entanglement of formation. http://arxiv.org/abs/quant-ph/0303045

* Current address: Dept. of Mathematics, Massachusetts Institute of Technology, Cambridge, MA 02139, USA 